\title{
Article \\ Structural Investigation of the Synthesized Few-Layer Graphene from Coal under Microwave
}

\author{
Faridul Islam ${ }^{1}$, Arash Tahmasebi ${ }^{1}$, Behdad Moghtaderi ${ }^{1}$ and Jianglong Yu ${ }^{1,2, *}$ \\ 1 Department of Chemical Engineering, School of Engineering, The University of Newcastle, \\ Callaghan, NSW 2308, Australia; faridul.islam@uon.edu.au (F.I.); arash.tahmasebi@newcastle.edu.au (A.T.); \\ behdad.moghtaderi@newcastle.edu.au (B.M.) \\ 2 Monash Research Institute of Science and Technology (Suzhou Industrial Park), Southeast \\ University-Monash University Joint Graduate School, Suzhou 215000, China \\ * Correspondence: jianglong.yu@monash.edu
}

check for updates

Citation: Islam, F.; Tahmasebi, A.; Moghtaderi, B.; Yu, J. Structural Investigation of the Synthesized Few-Layer Graphene from Coal under Microwave. Nanomaterials 2022, 12, 57. https://doi.org/ 10.3390/nano12010057

Academic Editors:

Toshihiro Shimada and

Lyubov G. Bulusheva

Received: 9 November 2021

Accepted: 21 December 2021

Published: 26 December 2021

Publisher's Note: MDPI stays neutral with regard to jurisdictional claims in published maps and institutional affiliations.

Copyright: (c) 2021 by the authors. Licensee MDPI, Basel, Switzerland. This article is an open access article distributed under the terms and conditions of the Creative Commons Attribution (CC BY) license (https:// creativecommons.org/licenses/by/ $4.0 /)$.

\begin{abstract}
This study focused on the structural investigation of few-layer graphene (FLG) synthesis from bituminous coal through a catalytic process under microwave heat treatment (MW). The produced FLG has been examined by Raman spectroscopy, XRD, TEM, and AFM. Coal was activated using the potassium hydroxide activation process. The FLG synthesis processing duration was much faster requiring only $20 \mathrm{~min}$ under the microwave radiation. To analyse few-layer graphene samples, we considered the three bands, i.e., D, G, and 2D, of Raman spectra. At $1300{ }^{\circ} \mathrm{C}$, the $\mathrm{P} 10 \%$ Fe sample resulted in fewer defects than the other catalyst percentages sample. The catalyst percentages affected the structural change of the FLG composite materials. In addition, the Raman mapping showed that the catalyst loaded sample was homogeneously distributed and indicated a few-layer graphene sheet. In addition, the AFM technique measured the FLG thickness around $4.5 \mathrm{~nm}$. Furthermore, the HRTEM images of the P10\% Fe sample contained a unique morphology with 2-7 graphitic layers of graphene thin sheets. This research reported the structural revolution with latent feasibility of FLG synthesis from bituminous coal in a wide range.
\end{abstract}

Keywords: few-layer graphene; coal; Raman spectroscopy; catalyst; microwave

\section{Introduction}

In recent years, the focus on graphene in the research and commercial sectors has increased remarkably worldwide due to its novel properties such as thermodynamically stability, transparency, and higher mechanical strength and for its potential applications in several fields, such as in sensors [1], batteries [2], ultrafast photodetectors [3], transparent electrodes [4], and advanced nanocomposites [5]. Graphene is a sp²-bonded monolayer carbon atom arranged in a 2D honeycomb frame. It displays unique electronic properties with high mobility and transportation [6,7]. SLG has a zero bandgap structure, which affects its potential electronics applications and optical performance [8]. In contrast, FLG has attracted more commercial applications due to the potential to control electronic states using interlayer connections [9]. Currently, the synthesis of SLG and FLG can be achieved using several methods such as the liquid exfoliation of graphite [10], epitaxy growth in an ultrahigh vacuum [11], mechanical cleavage [12], chemical vapour deposition (CVD) [13], chemical reduction [14], etc. Each of the techniques has some drawbacks that are not feasible for the mass production of graphene [15]. However, these techniques are expensive, and the production processes also contain toxic chemicals and long processing times. Thus, there is a need to establish a cost-effective process that is a fast and simple technique and has scalable production [16]. Among the various methods, the CVD procedure is the most promising technique to make a high-quality mono- or few-layer graphene with large coverage areas using catalytic substrates and hydrocarbon gases [17,18].

In addition, coal is an inexpensive and plentiful material worldwide, leading to alternative applications [19]. Coals and food waste have also been used as solid carbon 
sources instead of gaseous hydrocarbons to produce graphene [20]. Moreover, the graphite materials are used as a precursor to synthesize the graphene oxide, a time-consuming modified Hummers reduction process [21]. These days, MW heating plays a significant role in processing many materials. It has an interaction capacity with materials at a molecular level, and its polarization plays an important role in heating materials [22]. Moreover, the heating equality depends on the microwave extrinsic properties (MW frequency, cavity, and power amplitude) and sample intrinsic properties (size and shape). The sample shape also plays a crucial role in MW heating consistency and heating rate [23,24]. The MWassisted graphene synthesis provides extra benefits compared to the conventional synthesis methods. It has also been used to synthesise many graphene-derivative products, such as reduced graphene oxide ( $\mathrm{rGO}$ [25], graphene nanoribbons (GNRs) [26], and graphene oxide (GO) [27], which are frequently used in supercapacitors and battery applications for energy storage $[28,29]$.

Carbon and its derivatives such as graphite, carbon nanotubes (CNTs), and graphene are also synthesized using MW radiation. Carbon materials have an excellent MW absorption capacity due to the delocalisation of $\mathrm{pi}(\pi)$ electrons from the $\mathrm{sp}^{2}$ hybridized carbon atom [30]. However, the CVD method synthesises the multilayer graphene, which has a multiplicative effect with a better diffusion barrier than SLG [31]. The properties of FLGs, such as their electronic band structure, depend on the samples due to numerous crystallographic stacking orders. Therefore, the FLG is used widely in various sectors due to its potential capacity to control the electronic states through an interlayer interaction [32]. Raman spectroscopy has been extensively used to analyse graphite materials at the electronic band arrangements and vibrational ranges using the double-resonance Raman scattering mechanism [33]. The principal features of the Raman spectra such as the $\mathrm{D}, \mathrm{G}$, and 2D bands alter the location, which is related to the structural and electronic properties of composite materials [34].

With the increasing benefits of graphene-based nanotechnologies, there is a high demand to develop the production techniques for high-quality FLG. However, the industrial sector also requires cost- and time-efficient graphene production methods with a way to control layer thickness. The present work synthesized FLG from bituminous coal using a catalytic graphitization process (iron (III) nitrate nonahydrate) with MW heating for 20 min at $1300^{\circ} \mathrm{C}$. Raman spectra and mapping were applied to determine numerous aspects of the graphene produced. The fabricated FLG samples were analysed using XRD, Raman spectroscopy, TEM, and AFM.

\section{Materials and Methods}

\subsection{Materials and Sample Preparation}

The Australian bituminous coal was activated using a potassium hydroxide $(\mathrm{KOH})$ activation process to increase the porosity of FLG composite materials. The raw coal was heated at a fixed rate of $\mathrm{N}_{2}$ flow $(200 \mathrm{~mL} / \mathrm{min})$ for $30 \mathrm{~min}$ by the electric furnace (CarboliteVST $12 / 300, \mathrm{UK})$ at $600{ }^{\circ} \mathrm{C}\left(10^{\circ} \mathrm{C} / \mathrm{min}\right)$ to remove the volatile matter and other lightweight compounds. The sample was then ground and sieved to $<63 \mu \mathrm{m}$ and was consequently activated by the potassium hydroxide $(\mathrm{KOH})$ at a ratio of 1:4 (coal: $\mathrm{KOH})$ followed by carbonization at a temperature of $900{ }^{\circ} \mathrm{C}$ [35]. According to sample weight percentage, the $\mathrm{Fe}\left(\mathrm{NO}_{3}\right)_{3} \cdot 9 \mathrm{H}_{2} \mathrm{O}(\geq 99.95 \%)$ (Merck, Germany) catalyst was mixed overnight with a sample at $2 \%, 5 \%, 10 \%$, and $20 \%$, and then $0.1 \mathrm{M}$ ammonia solution (25\%) was used individually and stirred for $10 \mathrm{~min}$. Finally, the slurry was washed with distilled water, filtered, and dried at $110{ }^{\circ} \mathrm{C}$. The $\mathrm{KOH}$-modified, iron-loaded porous samples were denoted as $\mathrm{P} 2 \% \mathrm{Fe}$, $\mathrm{P} 5 \% \mathrm{Fe}, \mathrm{P} 10 \% \mathrm{Fe}$, and $\mathrm{P} 20 \% \mathrm{Fe}$.

\subsection{Synthesis of the FLG Materials}

A custom modified quartz reactor and B-type (up to $1600^{\circ} \mathrm{C}$ ) thermocouple was used inside a MW oven (Tangshan microwave thermal instrument CO. Ltd.; Beijing, China) to synthesize and measure the sample temperatures, briefly explained in our previous 
study [36]. In addition, a $3 \mathrm{~g}$ sample for each experiment was treated continuously with $\mathrm{N}_{2}$ gas flow $(200 \mathrm{~mL} / \mathrm{min}$ ) through the quartz reactor for $30 \mathrm{~min}$ prior to the start of the experiment. The catalyst-loaded samples with different catalyst percentages, from $2 \%$ to $20 \%$, were graphitized at a temperature of $1300{ }^{\circ} \mathrm{C}$ for $20 \mathrm{~min}$ with the same $\mathrm{N}_{2}$ flow rate.

\subsection{Structural Analysis of the FLG Materials}

The crystallinity of FLG composite materials was investigated with a Horiba XploRA PLUS Raman microscope (HORIBA France) with a $532 \mathrm{~nm}$ wavelength, which indicated the three different bands such as $\mathrm{D} \approx 1350 \mathrm{~cm}^{-1}, \mathrm{G} \approx 1580 \mathrm{~cm}^{-1}$, and $2 \mathrm{D} \approx 2700 \mathrm{~cm}^{-1}$, which are used to quantify the graphitization degree of samples. The thicknesses and cross-sectional images of the FLG samples were measured using an Asylum Research Cypher AFM (Oxford Instruments, CA). In addition, the texture of the FLG samples was scrutinized by the transmission electron microscope (JEOL TEM 2100) at $200 \mathrm{kV}$. BET was used to calculate the surface area of the materials. The X-ray diffraction (XRD) (Bruker, Berlin, Germany) was used for crystallinity in a wide range of $10^{\circ}$ to $80^{\circ}$. Furthermore, the sample crystal sizes $(\mathrm{La})$ and heights $(\mathrm{Lc})$ with an interlayer spacing $\left(\mathrm{d}_{002}\right)$ were measured by the Scherrer and Bragg equation. In addition, their $\mathrm{g}$ factor values were determined by the Marie and Meiring rules [37]. The Raman mappings were detected by an electron multiplication CCD camera (EMCCD). The confocal imaging was $0.5 \mu \mathrm{m}$. The fine powder samples were used to focus the laser on. In addition, three samples were used for each material. The repeat scans and acquisition times were dependent on the signal-to-noise ratios of the samples. The Raman spectra were focussed through a $100 \times$ objective microscope and were optimized at the highest spectral counts.

\section{Results and Discussion}

\subsection{Morphological Analysis of the FLG Materials}

XRD diffraction profiles of the Fe catalyst-loaded samples at a temperature of $1300{ }^{\circ} \mathrm{C}$ are shown in Figure 1a. The two distinctive peak positions were at around $26^{\circ}$ and $42.5^{\circ}$, respectively, which can be assigned to 002 and 100 reflections of graphite, suggesting a typical graphitic structure [38]. The highest intensity peak was obtained for the $\mathrm{P} 10 \% \mathrm{Fe}$ sample. The P $20 \%$ Fe sample's intensity was $26^{\circ}$, which was less than the P10\% Fe sample, due to having a more amorphous carbon structure. The metallic Fe present at around $45.2^{\circ}$ was formed by the degradation of the iron oxide during the graphitization period. It is also represented as a nucleus to form metallic iron's graphitic layers [39]. Table 1 shows the structural parameters measured with the XRD using the Scherrer and Bragg and Marie and Meiring equations, such as the particle size (La), thickness (Lc), interlayer distance $\left(\mathrm{d}_{002}\right)$, and $\mathrm{g}$ factor [37]. The results showed that the crystal sizes for the $\mathrm{P} 2 \% \mathrm{Fe}$ of $1.42 \mathrm{~nm}, \mathrm{P} 5 \%$ Fe of $1.50 \mathrm{~nm}, \mathrm{P} 10 \%$ Fe of $1.98 \mathrm{~nm}$, and P20\% Fe of $1.79 \mathrm{~nm}$, as well as the thicknesses for the P2\% Fe of $3.07 \mathrm{~nm}, \mathrm{P} 5 \% \mathrm{Fe}$ of $3.24 \mathrm{~nm}, \mathrm{P} 10 \% \mathrm{Fe}$ of $4.27 \mathrm{~nm}$, and $\mathrm{P} 20 \% \mathrm{Fe}$ of $3.85 \mathrm{~nm}$. The P10\% Fe catalyst obtained the largest sizes and thicknesses. The results for the P20\% Fe sample were reduced due to the catalytic agglomeration effect and having a more disordered structure. The values for the degree of graphitization ( $\mathrm{g}$ factor) were $85.9 \%, 90.7 \%, 96.8 \%$, and $92.2 \%$, respectively (see Table 1 ). The highest graphitization was achieved by the P10\% Fe sample, with $96.8 \%$. Furthermore, it was found that the MW catalytic graphitization also assisted in reducing the interlayer spacing distances of the samples [40]. The interlayer distance $\left(\mathrm{d}_{002}\right)$ values were very close for all samples, showing that the crystal structures changed from disordered to ordered structures. The interlayer distance $\left(\mathrm{d}_{002}\right)$ values for the P2\% to P20\% Fe samples were in the range of $0.3357-0.3366 \mathrm{~nm}$, which suggested a turbostratic structure due to larger values than those of graphite $(0.335 \mathrm{~nm})$ [41]. At a heating temperature of $1300^{\circ} \mathrm{C}$, the results showed that the P10\% Fe samples had $d_{002}$ values of 0.3357 , which was close to the structure of graphitic carbon. Moreover, the highest graphitization value ( $\mathrm{g}$ factor) found was for the $\mathrm{P} 10 \% \mathrm{Fe}$ sample $(96.8 \%)$, which corresponded with the degradation of numerous aliphatic chains and functional groups [42]. 

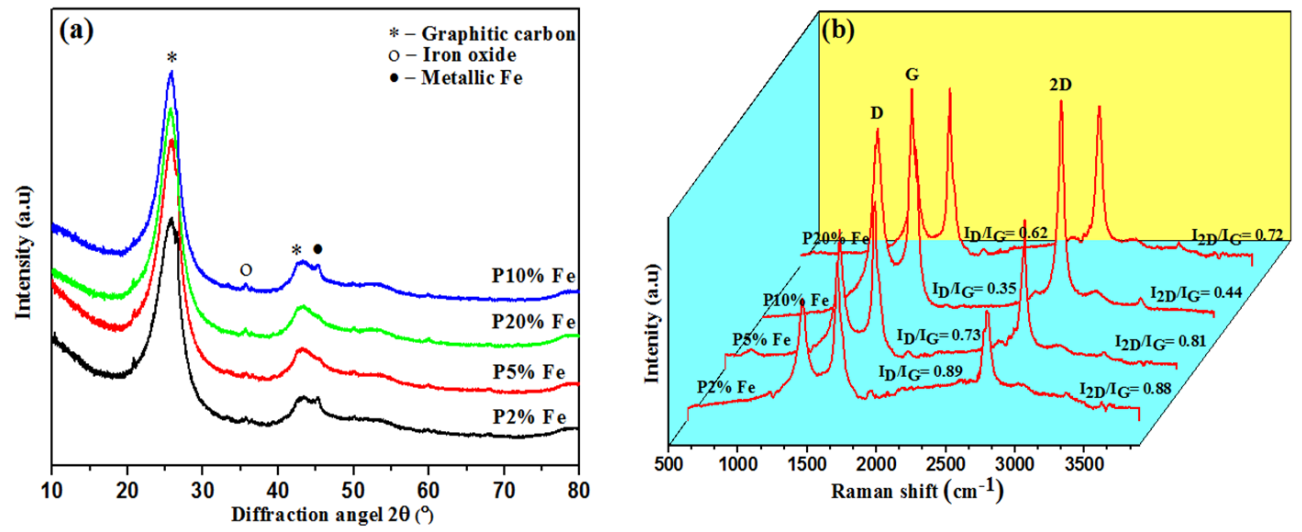

Figure 1. (a) XRD and (b) Raman spectra of the Fe-loaded samples.

Table 1. Structural properties at the different percentages of Fe catalyst.

\begin{tabular}{ccccc}
\hline $\begin{array}{c}\text { Catalyst Loading }(\% \text { of } \\
\text { Fe)/Parameters }\end{array}$ & P2 & P5 & P10 & P20 \\
\hline Interlayer spacing $\left(\mathrm{d}_{002}\right)(\mathrm{nm})^{1}$ & 0.3366 & 0.3362 & 0.3357 & 0.3361 \\
Crystal size $(\mathrm{Lc})(\mathrm{nm}){ }^{1}$ & 1.42 & 1.50 & 1.98 & 1.79 \\
In-plane crystal thickness $(\mathrm{La})(\mathrm{nm})$ & 3.07 & 3.24 & 4.27 & 3.85 \\
$\mathrm{I}_{\mathrm{D}} / \mathrm{I}_{\mathrm{G}}$ & 0.89 & 0.73 & 0.35 & 0.62 \\
Surface area $\left(\mathrm{m}^{2} \mathrm{~g}^{-1}\right)$ & 221.08 & 275.74 & 315.45 & 282.36 \\
"g" factor $(\%)^{2}$ & 85.9 & 90.7 & 96.8 & 92.1 \\
\hline
\end{tabular}

${ }^{1}$ Matches to the (002) graphitic plane, which is calculated from XRD data. ${ }^{2}$ The degree of graphitization value measured from $\mathrm{g}=\left(0.344-\mathrm{d}_{002}\right) /(0.344-0.3354)$.

The adsorption-desorption isotherm measured the textural properties of composite samples. The P10\% Fe sample-specific surface area was $315.45 \mathrm{~m}^{2} \mathrm{~g}^{-1}$, which was higher than the other percentages (see Table 1). It has been found that $\mathrm{KOH}$-activated samples have higher surface areas than steam-activated single and dual catalyst loading samples $\left(109.3 \mathrm{~m}^{2} \mathrm{~g}^{-1}\right.$ and $\left.175.61 \mathrm{~m}^{2} \mathrm{~g}^{-1}\right)[36,43]$.

Raman spectroscopy has broadly been applied to scrutinize carbon nanostructures because it is a nondestructive tool and is sensitive enough to determine molecular bonding and geometric structures [44]. The Raman spectra for the graphene and graphite were screened to $1000-3000 \mathrm{~cm}^{-1}$ area and showed three prominent peaks such as $\mathrm{D}, \mathrm{G}$, and 2D. At $1350 \mathrm{~cm}^{-1}$, the $\mathrm{D}$ peak was attributed to defects present in the samples, and its intensity also indicated the amount of disordered structure. The $G$ peak $\left(1580 \mathrm{~cm}^{-1}\right)$ corresponded to the $\mathrm{sp}^{2}$-hybridization, and the peak position and intensity are influential in determining the $\mathrm{f}$ graphene layer numbers [45]. The 2D peak $\left(2700 \mathrm{~cm}^{-1}\right)$ arose from the two double resonance phenomena with equal but opposite wave vector phonons and is the second most prominent graphite band. Ferrari and his co-workers investigated that the multilayer graphene electronic band structure has changed for the 2D band position, intensity, and shape [46].

The Raman spectra of P2\% to P20\% are recorded in Figure 1b. The disordered and ordered structures are represented by the D and G bands in the Raman spectra, and the $\mathrm{I}_{\mathrm{D}} / \mathrm{I}_{\mathrm{G}}$ ratio showed the graphitization degree. In addition, the $\mathrm{I}_{\mathrm{D}} / \mathrm{I}_{\mathrm{G}}$ results showed $\mathrm{P} 2 \%$ Fe was 0.89 , P $5 \%$ Fe was 0.73 , P10\% Fe was 0.35 , and P20\% Fe was 0.862 , with the P10\% Fe sample containing the lowest value (0.35) (Figure 2a). It showed that the homogenous and continuous graphene carbon nanostructures were formed in the P10\% Fe sample [47]. However, the degree of graphitization value for the $\mathrm{P} 20 \%$ was higher than the $\mathrm{P} 10 \%$ sample due to the catalytic aggregation, and a high amount of disordered structures were present in the sample [48]. 

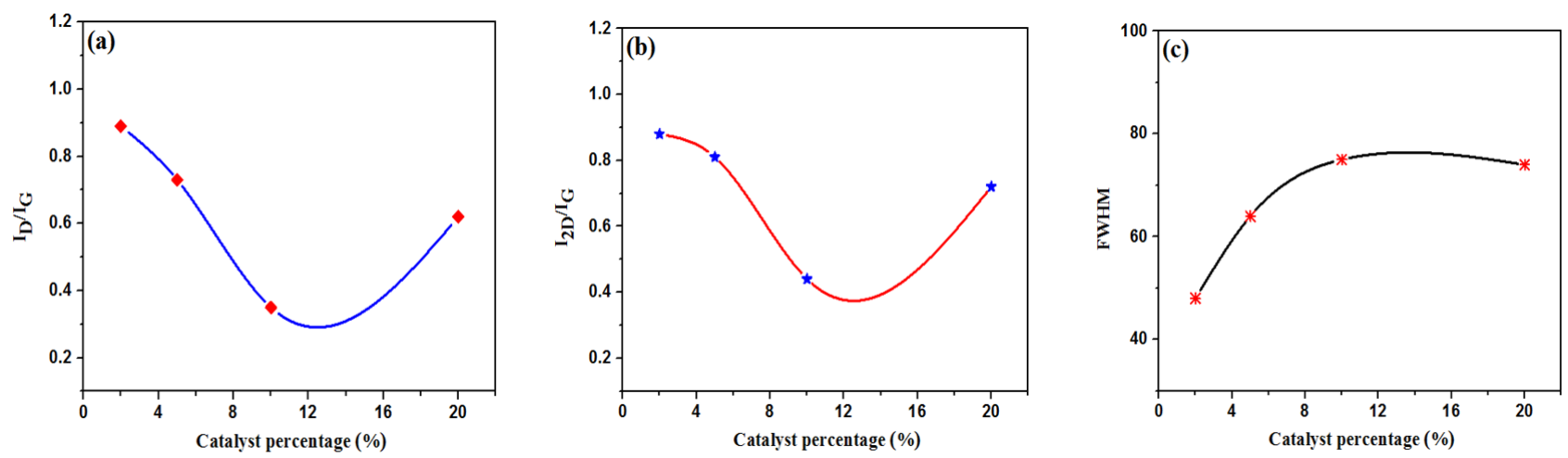

Figure 2. Results for: (a) $\mathrm{I}_{\mathrm{D}} / \mathrm{I}_{\mathrm{G}} ;$ (b) $\mathrm{I}_{2 \mathrm{D}} / \mathrm{I}_{\mathrm{G}}$; and (c) FWHM of the $2 \mathrm{D}$ band function for the different percentages of the Fe catalyst.

Another prominent 2D band was detected at $2700 \mathrm{~cm}^{-1}$, which is frequently used to confirm the thickness of the graphene. In addition, the 2D peak is highly influential because the duel- or triple-resonance produces a photoexcited electron-hole pair with a different energy. The layer numbers changed with the nature of the 2D peak, which indicated that the electronic band structure changed. Moreover, the 2D band positions lifted to a higher number as percentages of the catalyst were increased, which corresponded to the increase in the number of graphene layers [49] (see Table 2). Furthermore, the $I_{2 D} / I_{G}$ ratio determined the number of graphene layers. The lowest ratio for the $\mathrm{I}_{2 \mathrm{D}} / \mathrm{I}_{\mathrm{G}}$ was 0.44 , which was observed for the P10\% Fe sample, and it corresponded to the FLG structure (Figure 2b) [47]. Moreover, the $\mathrm{I}_{2 \mathrm{D}} / \mathrm{I}_{\mathrm{D}}$ ratio signified the overall crystalline structures of all samples analysed, shown in Table 2 . The P10\% Fe sample obtained the highest $\mathrm{I}_{2 \mathrm{D}} / \mathrm{I}_{\mathrm{D}}$ value of 1.24 , which indicated a longer graphitic structure [50]. The full width half maximum (FWHM) of the 2D band measured the number of graphene layers, which is shown in Figure 2c [51]. The FWHM values for the different percentages of catalyst were $48 \pm 0.15 \mathrm{~cm}^{-1}$ for $\mathrm{P} 2 \% \mathrm{Fe}, 64 \pm 0.17 \mathrm{~cm}^{-1}$ for $\mathrm{P} 5 \% \mathrm{Fe}, 75 \pm 0.26 \mathrm{~cm}^{-1}$ for $\mathrm{P} 10 \% \mathrm{Fe}$, and $74 \pm 0.24 \mathrm{~cm}^{-1}$ for $\mathrm{P} 20 \% \mathrm{Fe}$, which suggest the formation of FLG, which is supported by the findings in other studies $[47,52]$ (Table 2).

Table 2. Raman spectroscopy results of P2\% to P20\% Fe-loaded sample.

\begin{tabular}{ccccc}
\hline Fe (\%) Loading/Parameters & P2 & P5 & P10 & P20 \\
\hline Position of 2D $\left(\mathrm{cm}^{-1}\right)$ & $2698 \pm 0.19$ & $2699 \pm 0.21$ & $2702 \pm 0.24$ & $2703 \pm 0.22$ \\
$\mathrm{I}_{2 \mathrm{D}} / \mathrm{I}_{\mathrm{G}}$ & 0.88 & 0.81 & 0.44 & 0.72 \\
$\mathrm{I}_{2 \mathrm{D}} / \mathrm{I}_{\mathrm{D}}$ & 0.98 & 1.11 & 1.24 & 1.17 \\
FWHM (2D) & $48 \pm 0.15$ & $64 \pm 0.17$ & $75 \pm 0.26$ & $74 \pm 0.24$ \\
\hline
\end{tabular}

The Raman mapping was applied to determine the thicknesses of graphene [53]. The results of the Raman intensity mapping for the P10\% Fe sample on a quartz substrate are represented in Figures 3 and 4. The peak area locations for the three (3) bands were $1350 \mathrm{~cm}^{-1}, 1580 \mathrm{~cm}^{-1}$, and $2700 \mathrm{~cm}^{-1}$, which are displayed in red, green, and blue, respectively. The mapping indicated that the sheets were homogeneously spread on the quartz substrate (Figures 3 and 4). The brighter zones of the D band showed the sample's high intensity (Figure 3). In addition, the defects were larger in the perkier region, ascribed to edge defects. The degree of graphitization ratios $\left(\mathrm{I}_{\mathrm{D}} / \mathrm{I}_{\mathrm{G}}\right)$ for the points (1), (2), (3), (4), (5), and (6) were $0.15,0.19,0.28,0.32,0.34$, and 0.37 respectively. The defect ratios for points (1)-(3) were $0.15-0.28$. However, points (4)-(6) were $0.32-0.37$, indicating that the lower height of the D band was correlated with the high quality of the FLG, and the other findings are supported. Furthermore, the D band arises from the red boundary. The histogram of $\mathrm{I}_{\mathrm{D}} / \mathrm{I}_{\mathrm{G}}$ ratio of 600 data points was obtained using the Raman mapping. It is clear from the 
histogram graph that the $\mathrm{I}_{\mathrm{D}} / \mathrm{I}_{\mathrm{G}}$ ratio of all samples remained the same value, and the low intensity of the D band represents the FLG obtained.

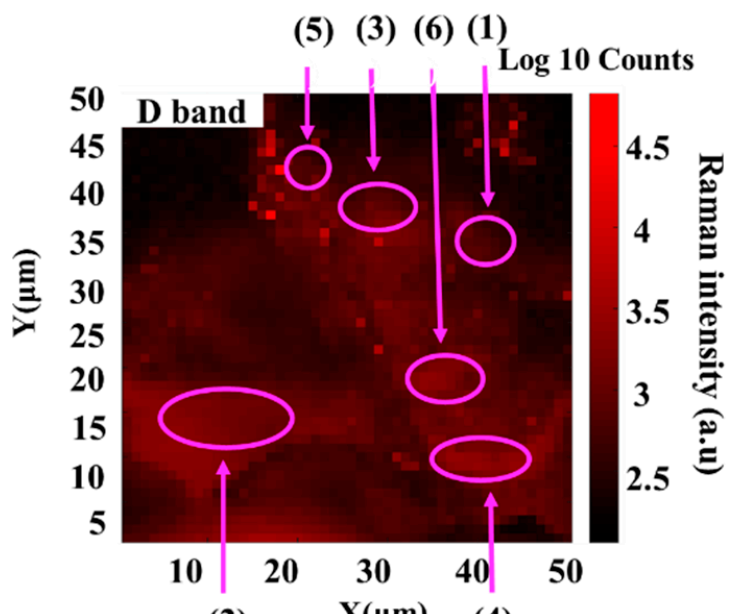

(2)

(a)

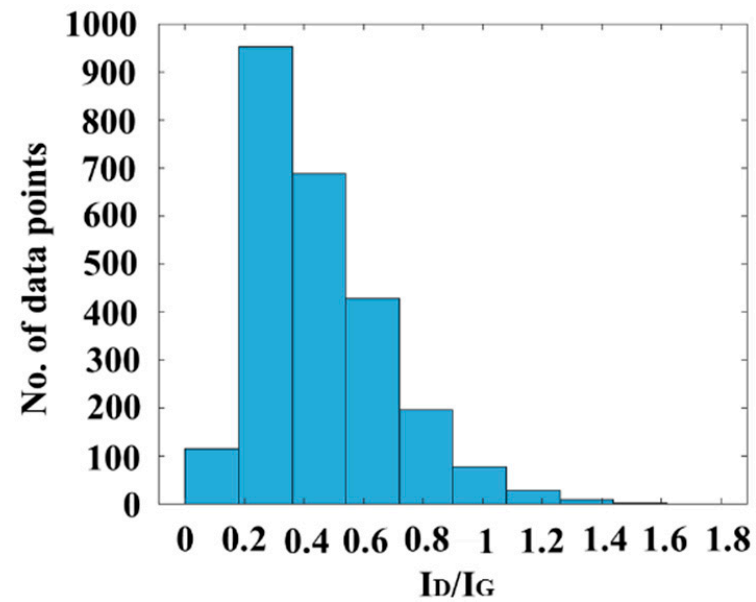

(c)

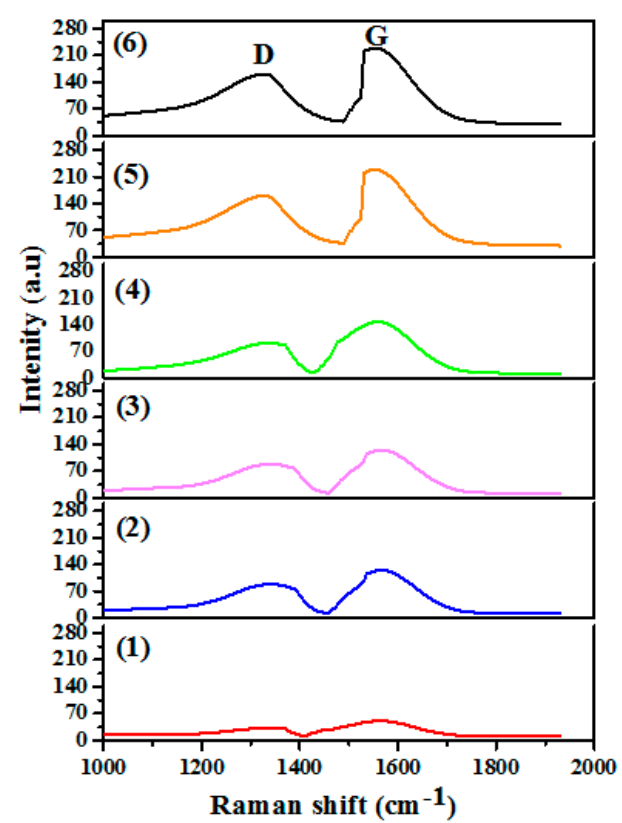

(b)

Figure 3. Raman mapping for the $\mathrm{D}$ band and a histogram of the $\mathrm{I}_{\mathrm{D}} / \mathrm{I}_{\mathrm{G}}$ ratio of the $\mathrm{P} 10 \%$ sample. 


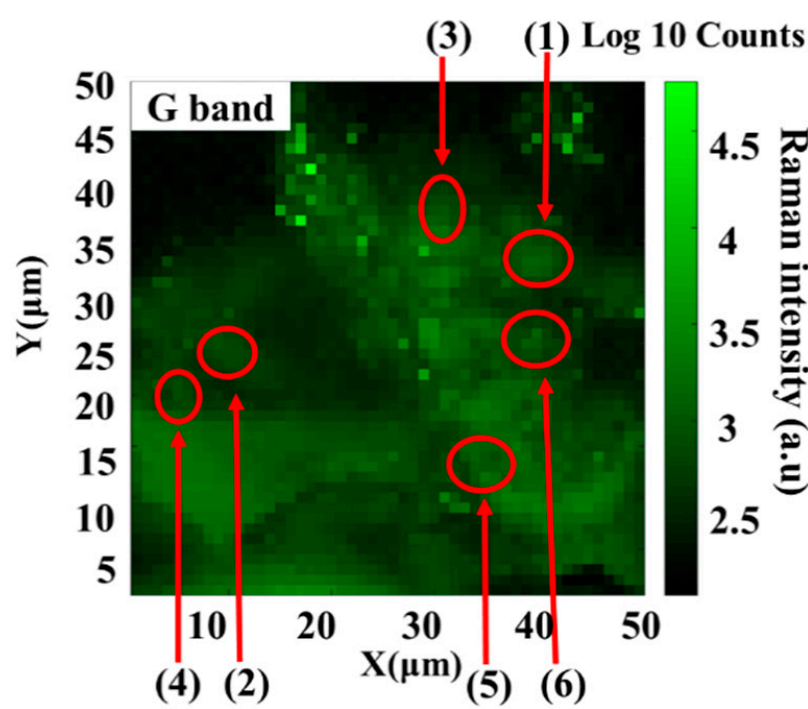

(a)

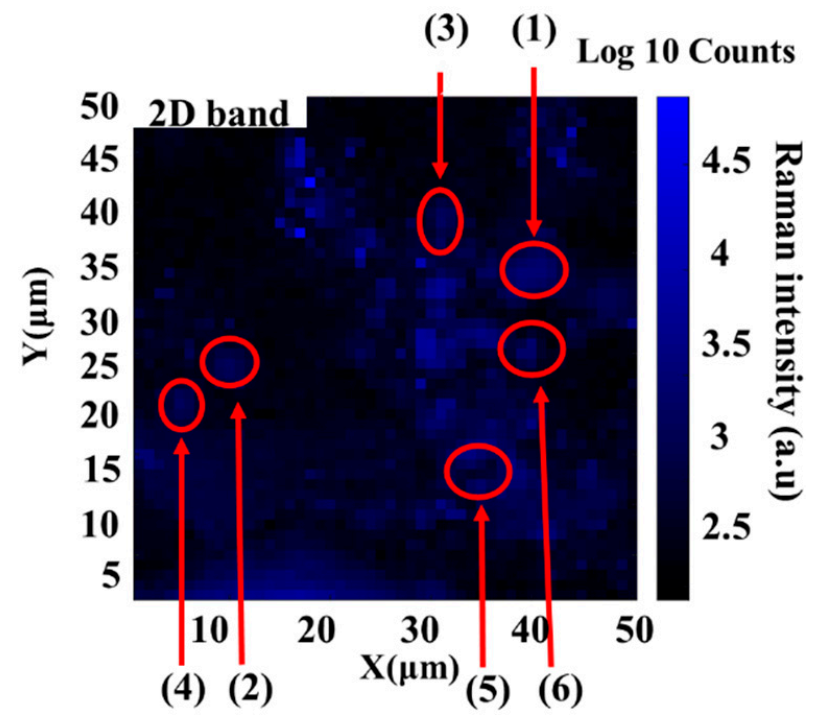

(b)

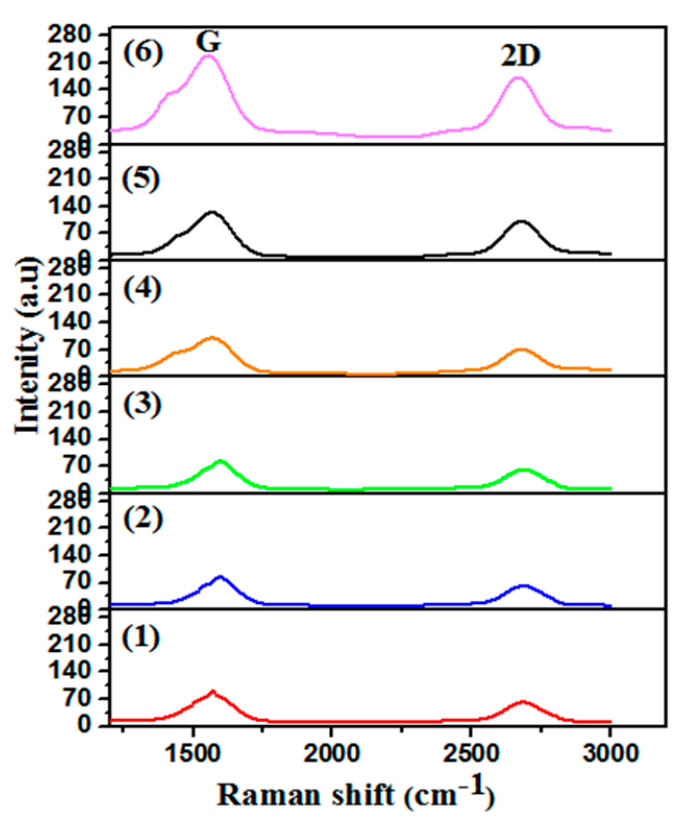

(c)

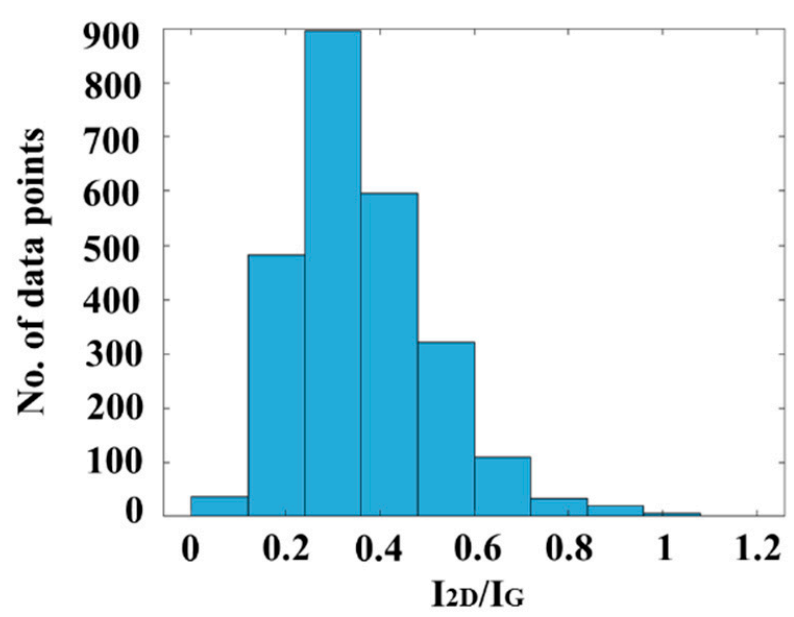

(d)

Figure 4. $\mathrm{G}$ and $2 \mathrm{D}$ bands Raman mapping with a histogram of the $\mathrm{I}_{2 \mathrm{D}} / \mathrm{I}_{\mathrm{G}}$ ratios of $\mathrm{P} 10 \%$ sample.

The Raman intensity mapping at various points for the $G$ and $2 D$ are presented in Figure 4 . The $\mathrm{G}$ and second order 2D bands rise from the green and navy-blue boundaries. Both bands have brighter areas and defect zones. The $\mathrm{I}_{2 \mathrm{D}} / \mathrm{I}_{\mathrm{G}}$ intensity ratio indicated the layer numbers of the graphene sheets, which are obtained from the Raman mapping. The $\mathrm{I}_{2 \mathrm{D}} / \mathrm{I}_{\mathrm{G}}$ intensity ratios were around $78 \%$ for points (1)-(4), 0.45 to 0.51 . However, for points (5) and (6), the $\mathrm{I}_{2 \mathrm{D}} / \mathrm{I}_{\mathrm{G}}$ values were 0.68 and 0.77 , respectively, which was remarkably high and indicated that the FLG formed. The histogram results also correlated with the $\mathrm{I}_{2 \mathrm{D}} / \mathrm{I}_{\mathrm{G}}$ ratios exposed in Figure 4 [54].

\subsection{AFM and TEM Examine the FLG Materials}

Morphological changes of the P10\% Fe sample were examined using AFM, and the results are displayed in Figure 5. The thickness of the graphene was measured with the AFM technique by studying the upper view image and the cross-sectional of the composite materials [55]. Figure 5 shows that the graphene sheets were sound-exfoliated 
and that the average sheet thickness was around $4.5 \mathrm{~nm}$, which indicated the existence of FLG sheets [56].

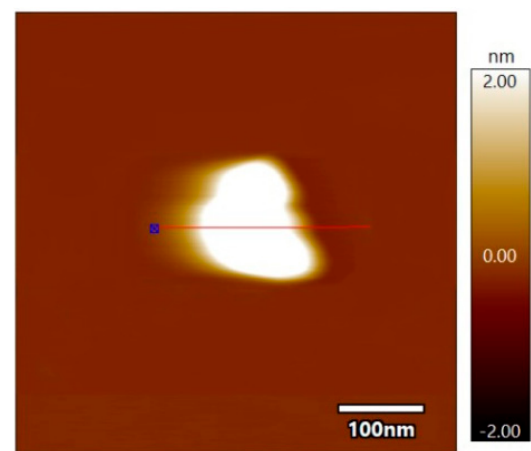

(a)

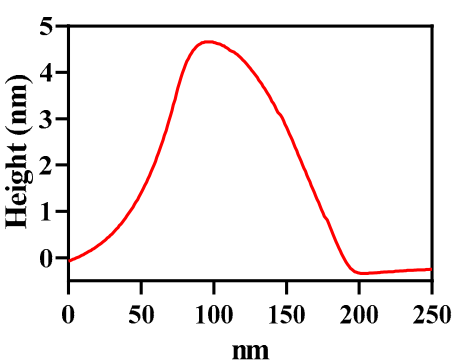

(b)

Figure 5. AFM image of the P10\% Fe sample with corresponding line profile.

The structure and morphology were further investigated by employing TEM to confirm the FLG materials. The TEM micrograph for the P10\% Fe sample showed FLGlike nanosheets at numerous magnifications on a lacy carbon grid (Figure 6a,b). The graphene plate was thin, and the plane with the wrinkles formed the back foldaway and touched the edge because of the transfer method. A transition metal such as Fe could reduce the melting temperature of the Fe and carbon due to their d-electron configuration and ionization abilities. The amorphous carbon melted over the catalyst at the supersaturation point of Fe-C. As a result, the graphitic layer was formed due to the dissolution and precipitation mechanism, whereas the catalysts worked as nuclei $[57,58]$. In addition, the $\mathrm{Fe}-\mathrm{C}$ eutectic point was $1148^{\circ} \mathrm{C}$, which was recorded from the $\mathrm{Fe}-\mathrm{C}$ phase diagram [59]. The high-resolution HRTEM images of the P10\% Fe sample in the selected regions highlighted the distorted nanosheets containing around 2-7 layers (Figure 6c,d). The KOH-activated sample achieved a fewer number of layers of graphene compared to the steam-activated sample [43]. 

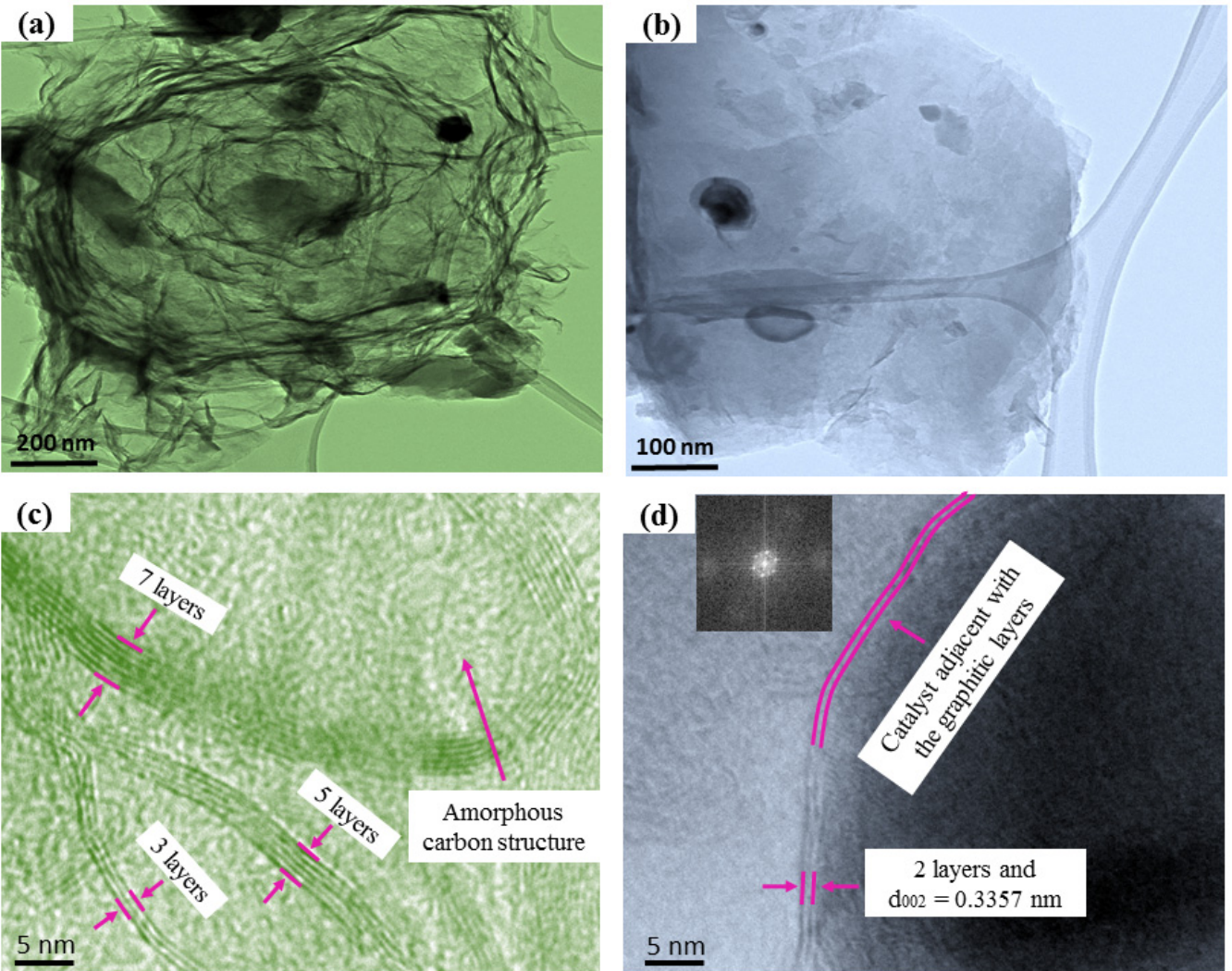

Figure 6. (a) and (b): TEM of the P10\% sample with different magnifications. (c,d): the HRTEM showing the FLG sheets (and the FFT image in the inset of (d)).

The HRTEM images also identified that the interlayer distance was around $0.34 \mathrm{~nm}$ (Figure 6d), which resembled the plane structure of FLG (002). It also agreed with the XRD data, as mentioned above. Furthermore, the fast Fourier transform (FFT) image (inset of Figure $6 \mathrm{~d}$ ) showed the hexagonal spot configuration. It confirmed the six-fold symmetry graphene features with the crystalline nature of the materials [60].

\section{Conclusions}

The coal-based synthesis of FLG was fabricated through potassium hydroxide modification with an MW graphitization technique. It was found that the catalyst loading, microwave temperature, and potassium hydroxide activation played significant roles in manufacturing the FLG composite materials. The synthesis of the P10\% Fe-loaded sample at a heating temperature of $1300{ }^{\circ} \mathrm{C}$ created a unique morphology with $2-7$ graphitic layers and lower defect levels, demonstrating that more regular and continuous thin sheets of graphene were formed. The catalyst loading percentages determined the structural change. The results of the TEM analyses revealed the sheets of the synthesized graphene (P10\% $\mathrm{Fe}$ ). The Raman mapping measurements showed that at $1300{ }^{\circ} \mathrm{C}$, the P10\% Fe-loaded sample was homogeneously distributed. The average detected $\mathrm{I}_{\mathrm{D}} / \mathrm{I}_{\mathrm{G}}$ ratio was around 0.35 , and the highest $\mathrm{I}_{2 \mathrm{D}} / \mathrm{I}_{\mathrm{G}}$ values were $0.68-0.77$, indicating a sheet of FLG. Moreover, the AFM technique measured that the thickness of the FLG was around $4.5 \mathrm{~nm}$. The few-layer graphene has several potential applications in many fields such as energy storage (lithiumion battery and supercapacitor), biomedical applications to targeted drug delivery, sensors, membranes, and the electronics arena.

Author Contributions: F.I. conducted the experimental work and wrote the manuscript with support from A.T. and J.Y. The manuscript writing-review and editing, F.I., A.T., B.M. and J.Y.; supervision under J.Y. and B.M.; project administration, J.Y. The listed authors played an intellectual role in the 
work and decided to publish this manuscript. All authors have read and agreed to the published version of the manuscript.

Funding: This project was supported by the RTPFEEOFF and RTPSTIPEND schemes and PGRSS (G-1010643) of the University of Newcastle, Australia.

Institutional Review Board Statement: Not applicable.

Informed Consent Statement: Not applicable.

Data Availability Statement: Data contained within this article.

Conflicts of Interest: The authors declare no conflict of interest.

\section{References}

1. Díaz, P.; González, Z.; Santamaría, R.; Granda, M.; Menéndez, R.; Blanco, C. Enhancing energy density of carbon-based supercapacitors using Prussian Blue modified positive electrodes. Electrochim. Acta 2016, 212, 848-855. [CrossRef]

2. Dobrota, A.S.; Pašti, I.A.; Mentus, S.V.; Johansson, B.; Skorodumova, N.V. Functionalized graphene for sodium battery applications: The DFT insights. Electrochim. Acta 2017, 250, 185-195. [CrossRef]

3. Xia, F.; Mueller, T.; Lin, Y.-M.; Valdes-Garcia, A.; Avouris, P. Ultrafast graphene photodetector. Nat. Nanotechnol. 2009, 4, 839-843. [CrossRef]

4. Kim, K.S.; Zhao, Y.; Jang, H.; Lee, S.Y.; Kim, J.M.; Kim, K.S.; Ahn, J.-H.; Kim, P.; Choi, J.-Y.; Hong, B.H. Large-scale pattern growth of graphene films for stretchable transparent electrodes. Nature 2009, 457, 706-710. [CrossRef]

5. Sierra, U.; Mercado, A.; Cuara, E.; Barriga-Castro, E.D.; Cortés, A.; Gallardo-Vega, C.; Fernández, S. Coke-derived few layer graphene-like materials by mild planetary milling exfoliation. Fuel 2020, 262, 116455. [CrossRef]

6. Geim, A.K.; Novoselov, K.S. The rise of graphene. In Nanoscience and Technology: A Collection of Reviews from Nature Journals; World Scientific: Singapore, 2010; pp. 11-19.

7. Tse, W.-K.; Hwang, E.; Das Sarma, S. Ballistic hot electron transport in graphene. Appl. Phys. Lett. 2008, 93, 023128. [CrossRef]

8. Neto, A.C.; Guinea, F.; Peres, N.M.; Novoselov, K.S.; Geim, A.K. The electronic properties of graphene. Rev. Mod. Phys. 2009, 81, 109. [CrossRef]

9. Castro, E.V.; Novoselov, K.; Morozov, S.; Peres, N.; Dos Santos, J.L.; Nilsson, J.; Guinea, F.; Geim, A.; Neto, A.C. Biased bilayer graphene: Semiconductor with a gap tunable by the electric field effect. Phys. Rev. Lett. 2007, 99, 216802. [CrossRef] [PubMed]

10. Hernandez, Y.; Nicolosi, V.; Lotya, M.; Blighe, F.M.; Sun, Z.; De, S.; McGovern, I.; Holland, B.; Byrne, M.; Gun'Ko, Y.K. High-yield production of graphene by liquid-phase exfoliation of graphite. Nat. Nanotechnol. 2008, 3, 563-568. [CrossRef] [PubMed]

11. Berger, C.; Song, Z.; Li, T.; Li, X.; Ogbazghi, A.Y.; Feng, R.; Dai, Z.; Marchenkov, A.N.; Conrad, E.H.; First, P.N. Ultrathin epitaxial graphite: 2D electron gas properties and a route toward graphene-based nanoelectronics. J. Phys. Chem. B 2004, 108, 19912-19916. [CrossRef]

12. Novoselov, K.S.; Geim, A.K.; Morozov, S.V.; Jiang, D.; Zhang, Y.; Dubonos, S.V.; Grigorieva, I.V.; Firsov, A.A. Electric field effect in atomically thin carbon films. Science 2004, 306, 666-669. [CrossRef]

13. Muñoz, R.; Gómez-Aleixandre, C. Review of CVD synthesis of graphene. Chem. Vap. Depos. 2013, 19, 297-322. [CrossRef]

14. Abdolhosseinzadeh, S.; Asgharzadeh, H.; Kim, H.S. Fast and fully-scalable synthesis of reduced graphene oxide. Sci. Rep. 2015, 5, 1-7. [CrossRef] [PubMed]

15. Galindo, B.; Alcolea, S.G.; Gómez, J.; Navas, A.; Murguialday, A.O.; Fernandez, M.P.; Puelles, R. Effect of the number of layers of graphene on the electrical properties of TPU polymers. IOP Conf. Ser. Mater. Sci. Eng. 2014, 64, 012008. [CrossRef]

16. Krane, N. Preparation of Graphene. Selected Topics in Physics: Physics of Nanoscale Carbon 2011. Available online: https: //www.physik.fu-berlin.de/einrichtungen/ag/ag-reich/lehre/Archiv/ss2011/docs/Nils_Krane-Handout.pdf (accessed on 28 October 2021).

17. Li, X.; Cai, W.; An, J.; Kim, S.; Nah, J.; Yang, D.; Piner, R.; Velamakanni, A.; Jung, I.; Tutuc, E. Large-area synthesis of high-quality and uniform graphene films on copper foils. Science 2009, 324, 1312-1314. [CrossRef]

18. Reina, A.; Jia, X.; Ho, J.; Nezich, D.; Son, H.; Bulovic, V.; Dresselhaus, M.S.; Kong, J. Large area, few-layer graphene films on arbitrary substrates by chemical vapor deposition. Nano Lett. 2009, 9, 30-35. [CrossRef]

19. Wang, G.; Zhang, L.; Zhang, J. A review of electrode materials for electrochemical supercapacitors. Chem. Soc. Rev. 2012, 41, 797-828. [CrossRef] [PubMed]

20. Vijapur, S.H.; Wang, D.; Botte, G.G. Raw coal derived large area and transparent graphene films. ECS Solid State Lett. 2013, 2, M45. [CrossRef]

21. Bi, H.; Wan, S.; Cao, X.; Wu, X.; Zhou, Y.; Yin, K.; Su, S.; Ma, Q.; Sindoro, M.; Zhu, J. A general and facile method for preparation of large-scale reduced graphene oxide films with controlled structures. Carbon 2019, 143, 162-171. [CrossRef]

22. Menéndez, J.; Arenillas, A.; Fidalgo, B.; Fernández, Y.; Zubizarreta, L.; Calvo, E.G.; Bermúdez, J.M. Microwave heating processes involving carbon materials. Fuel Process. Technol. 2010, 91, 1-8. [CrossRef]

23. Fung, D.Y.; Cunningham, F. Effect of microwaves on microorganisms in foods. J. Food Prot. 1980, 43, 641-650. [CrossRef] 
24. Soto-Reyes, N.; Temis-Pérez, A.L.; López-Malo, A.; Rojas-Laguna, R.; Sosa-Morales, M.E. Effects of shape and size of agar gels on heating uniformity during pulsed microwave treatment. J. Food Sci. 2015, 80, E1021-E1025. [CrossRef]

25. Jiang, F.; Yu, Y.; Wang, Y.; Feng, A.; Song, L. A novel synthesis route of graphene via microwave assisted intercalation-exfoliation of graphite. Mater. Lett. 2017, 200, 39-42. [CrossRef]

26. Amiri, A.; Sadri, R.; Shanbedi, M.; Ahmadi, G.; Kazi, S.; Chew, B.; Zubir, M.N.M. Synthesis of ethylene glycol-treated graphene nanoplatelets with one-pot, microwave-assisted functionalization for use as a high performance engine coolant. Energy Convers. Manag. 2015, 101, 767-777. [CrossRef]

27. Zhu, Y.; Murali, S.; Stoller, M.D.; Velamakanni, A.; Piner, R.D.; Ruoff, R.S. Microwave assisted exfoliation and reduction of graphite oxide for ultracapacitors. Carbon 2010, 48, 2118-2122. [CrossRef]

28. Liu, T.; Chai, H.; Jia, D.; Su, Y.; Wang, T.; Zhou, W. Rapid microwave-assisted synthesis of mesoporous nimoo4 nanorod/reduced graphene oxide composites for high-performance supercapacitors. Electrochim. Acta 2015, 180, 998-1006. [CrossRef]

29. Zhou, X.; Shi, J.; Liu, Y.; Su, Q.; Zhang, J.; Du, G. Microwave-assisted synthesis of hollow cuo-Cu2O nanosphere/graphene composite as anode for lithium-ion battery. J. Alloys Compd. 2014, 615, 390-394. [CrossRef]

30. Kim, T.; Lee, J.; Lee, K.-H. Microwave heating of carbon-based solid materials. Carbon Lett. 2014, 15, 15-24. [CrossRef]

31. Prasai, D.; Tuberquia, J.C.; Harl, R.R.; Jennings, G.K.; Bolotin, K.I. Graphene: Corrosion-inhibiting coating. ACS Nano 2012, 6 , 1102-1108. [CrossRef] [PubMed]

32. Yao, W.; Xiao, D.; Niu, Q. Valley-dependent optoelectronics from inversion symmetry breaking. Phys. Rev. B 2008, 77, 235406. [CrossRef]

33. Thomsen, C.; Reich, S. Double resonant Raman scattering in graphite. Phys. Rev. Lett. 2000, 85, 5214. [CrossRef]

34. Malard, L.; Pimenta, M.A.; Dresselhaus, G.; Dresselhaus, M. Raman spectroscopy in graphene. Phys. Rep. 2009, 473, 51-87. [CrossRef]

35. Govind Raj, K.; Joy, P.A. Role of localized graphitization on the electrical and magnetic properties of activated carbon. J. Am. Ceram. Soc. 2017, 100, 5151-5161. [CrossRef]

36. Islam, F.; Tahmasebi, A.; Wang, R.; Yu, J. Structure of Coal-Derived Metal-Supported Few-Layer Graphene Composite Materials Synthesized Using a Microwave-Assisted Catalytic Graphitization Process. Nanomaterials 2021, 11, 1672. [CrossRef]

37. Yeh, T.-S.; Wu, Y.-S.; Lee, Y.-H. Graphitization of unburned carbon from oil-fired fly ash applied for anode materials of high power lithium ion batteries. Mater. Chem. Phys. 2011, 130, 309-315. [CrossRef]

38. Wang, R.; Lu, G.; Qiao, W.; Yu, J. Catalytic graphitization of coal-based carbon materials with light rare earth elements. Langmuir 2016, 32, 8583-8592. [CrossRef]

39. Xiong, W.; Zhou, Y.S.; Hou, W.J.; Guillemet, T.; Silvain, J.-F.; Gao, Y.; Lahaye, M.; Lebraud, E.; Xu, S.; Wang, X. Solid-state graphene formation via a nickel carbide intermediate phase. RSC Adv. 2015, 5, 99037-99043. [CrossRef]

40. Kim, T.; Lee, J.; Lee, K.-H. Full graphitization of amorphous carbon by microwave heating. RSC Adv. 2016, 6, 24667-24674 [CrossRef]

41. Inagaki, M. New Carbons-Control of Structure and Functions; Elsevier: Amsterdam, The Netherlands, 2000.

42. Kim, Y.-J.; Yang, H.; Yoon, S.-H.; Korai, Y.; Mochida, I.; Ku, C.-H. Anthracite as a candidate for lithium ion battery anode. J. Power Sources 2003, 113, 157-165. [CrossRef]

43. Islam, F.; Wang, J.; Tahmasebi, A.; Wang, R.; Moghtaderi, B.; Yu, J. Microwave-Assisted Coal-Derived Few-Layer Graphene as an Anode Material for Lithium-Ion Batteries. Materials 2021, 14, 6468. [CrossRef] [PubMed]

44. Ferrari, A.C.; Basko, D.M. Raman spectroscopy as a versatile tool for studying the properties of graphene. Nat. Nanotechnol. 2013, 8, 235-246. [CrossRef] [PubMed]

45. Khan, M.F.; Iqbal, M.Z.; Iqbal, M.W.; Eom, J. Improving the electrical properties of graphene layers by chemical doping. Sci. Technol. Adv. Mater. 2014, 15, 055004. [CrossRef]

46. Ferrari, A.C.; Meyer, J.C.; Scardaci, V.; Casiraghi, C.; Lazzeri, M.; Mauri, F.; Piscanec, S.; Jiang, D.; Novoselov, K.S.; Roth, S. Raman spectrum of graphene and graphene layers. Phys. Rev. Lett. 2006, 97, 187401. [CrossRef]

47. Prekodravac, J.; Marković, Z.; Jovanović, S.; Holclajtner-Antunović, I.; Pavlović, V.; Todorović-Marković, B. Raman spectroscopy study of graphene thin films synthesized from solid precursor. Opt. Quantum Electron. 2016, 48, 115. [CrossRef]

48. Bîru, E.I.; Iovu, H. Graphene nanocomposites studied by Raman spectroscopy. Raman Spectrosc. 2018, 179, 179-201.

49. Ni, Z.; Wang, Y.; Yu, T.; Shen, Z. Raman spectroscopy and imaging of graphene. Nano Res. 2008, 1, 273-291. [CrossRef]

50. Sharma, B.; Schumann, T.; de Oliveira, M.H., Jr.; Lopes, J.M.J. Controlled synthesis and characterization of multilayer graphene films on the C-face of silicon carbide. Phys. Status Solidi 2017, 214, 1600721. [CrossRef]

51. Kim, K.; Coh, S.; Tan, L.Z.; Regan, W.; Yuk, J.M.; Chatterjee, E.; Crommie, M.; Cohen, M.L.; Louie, S.G.; Zettl, A. Raman spectroscopy study of rotated double-layer graphene: Misorientation-angle dependence of electronic structure. Phys. Rev. Lett. 2012, 108, 246103. [CrossRef]

52. Ferrari, A.C. Raman spectroscopy of graphene and graphite: Disorder, electron-phonon coupling, doping and nonadiabatic effects. Solid State Commun. 2007, 143, 47-57. [CrossRef]

53. Graf, D.; Molitor, F.; Ensslin, K.; Stampfer, C.; Jungen, A.; Hierold, C.; Wirtz, L. Raman mapping of a single-layer to double-layer graphene transition. Eur. Phys. J. Spec. Top. 2007, 148, 171-176. [CrossRef]

54. Gayathri, S.; Jayabal, P.; Kottaisamy, M.; Ramakrishnan, V. Synthesis of few layer graphene by direct exfoliation of graphite and a Raman spectroscopic study. Aip Adv. 2014, 4, 027116. [CrossRef] 
55. Ramalingam, P.; Pusuluri, S.T.; Periasamy, S.; Veerabahu, R.; Kulandaivel, J. Role of deoxy group on the high concentration of graphene in surfactant/water media. RSC Adv. 2013, 3, 2369-2378. [CrossRef]

56. Peng, K.-J.; Lin, Y.-H.; Wu, C.-L.; Lin, S.-F.; Yang, C.-Y.; Lin, S.-M.; Tsai, D.-P.; Lin, G.-R. Dissolution-and-reduction CVD synthesis of few-layer graphene on ultra-thin nickel film lifted off for mode-locking fiber lasers. Sci. Rep. 2015, 5, 1-10. [CrossRef]

57. Ōya, A.; Ōtani, S. Catalytic graphitization of carbons by various metals. Carbon 1979, 17, 131-137. [CrossRef]

58. Derbyshire, F.; Presland, A.; Trimm, D. Graphite formation by the dissolution-precipitation of carbon in cobalt, nickel and iron. Carbon 1975, 13, 111-113. [CrossRef]

59. Bystrzejewski, M. Synthesis of carbon-encapsulated iron nanoparticles via solid state reduction of iron oxide nanoparticles. $J$. Solid State Chem. 2011, 184, 1492-1498. [CrossRef]

60. Zan, R. Microscopy and Spectroscopy of Graphene: Atomic Scale Structure and Interaction with Foreign Atom Species; The University of Manchester: Manchester, UK, 2013. 